\title{
Erratum
}

\section{Mukaiyama Aldol-Prins Cyclizations with Ketones}

Brian Patterson, Scott D. Rychnovsky* Synlett 2004, 543.

In Table 1, entry 8, the major isomer arises from equatorial addition to menthone in accord with literature precedent. Corrected structure:<smiles>CCC1(CC2CC(Br)CC(CCc3ccccc3)O2)C[C@H](C)CCC1C(C)C</smiles> 